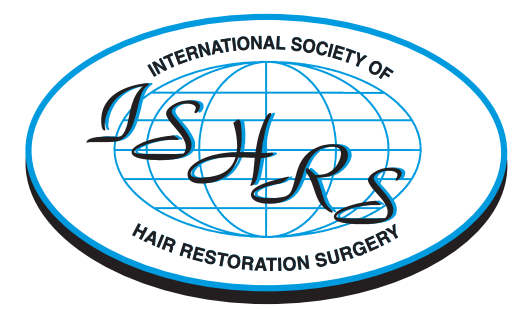

\section{Inside this issue}

President's Message ..

Co-editors' Messages Notes from the Editor Emeritus: Jerry E. Cooley, MD.

Case Studies:

Cicatricial Alopecia

Hypotrichia.

Atrichia.

Regional Hypertrichia

$142-146$

146-152

152-154

Harvesting Beard Hair for Scalp

Transplantation...

Beard Chat

Hair's the Question: Beard Hair

Transplantation.

How I Do It: New Disposable Cordless FUE Motor

ISHRS Members Urged to Join the AMA.

ISHRS Best Practices Survey Project: Who Does What

Meetings \& Studies: 4th AAHRS Annual Scientific

Meeting

ISHRS Regional Workshop for Assistant Training ....

Messages from the 2015 ASM

Program Chair.

Surgical Assistants Chair

Classified Ads.

\section{PLAN TO ATTEND!}

www.ishrs.org/AnnualMeeting.html

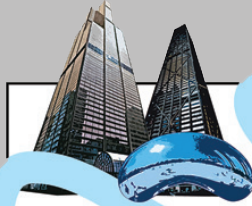

CHICAGO'15

ISHRS 23RD ANNUAL SCIENTIFIC MEETING SEPTEMBER 9-13

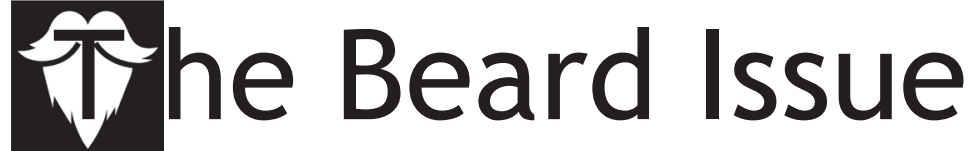

Robert H. True, MD, MPH, FISHRS New York, New York, USA editors@ISHRS.org

Welcome to "The Beard Issue" in which the entire issue will focus on beard hair reconstruction and harvesting. This is not an area that has been given a lot of attention in this (or any other) journal previously. Facial hair includes the eyebrows, eyelashes, beard, and moustache (mustache). Eyebrow and eyelash transplantation have been extensively explored in our literature and meetings, but the beard and moustache have not.

Such a focus is now timely as there is a worldwide increase in awareness and demand for facial hair transplantation of all kinds. In talking with our colleagues, I have learned that some are doing as many as 3-4 cases of beard and moustache transplantation per month. Many report that they are seeing an increasing number of patients who are seeking beard and moustache transplantation for cosmetic rather than reconstructive reasons. We hope this issue will provide a platform to begin coalescing and refining the art and science of beard and moustache restoration.

The issue will include a well-conceived comprehensive overview on the topic by Drs. Kapil Dua, Aman Dua, and Renu Kothottil followed by case presentations by Drs. Jeffrey Epstein, Bessam Farjo, Bijan Feriduni, James Harris, Antonio Ruston, Akaki Tsilosani, James Vogel, Bradley Wolf, and Ummer Yaseen and Shagufta Rather. I want to express my gratitude to all these surgeons for contributing examples of excellent work. In addition, Dr. Wasserbauer will challenge us with a beard hair quiz and How I do It will highlight a low-cost disposable motor for beard and scalp FUE. I think you will find this issue a good read.

\title{
Facial Hair Transplantation
}

\section{Kapil Dua, MBBS, MS, Aman Dua, MBBS, MD, and Renu Kothottil, MBBS, MD Ludhiana, Punjab, India drkapildua@akclinics.com}

Beards are great for rubbing when deep in thought, they block the sun from burning your face, they hide neck flab, and they suggest a life free from razor burn. And while some men have thick growth of facial hair, others may not, due to a variety of reasons, and yearn to have it. With more and more people knowing about the possibility of the beard and moustache reconstruction, many are now undergoing transplant in these areas, and they can have different facial hairstyles.

This trend of the growing popularity of facial hair restoration is also catching up with ISHRS members. As was reported in the ISHRS 2013 Practice Census, about $7 \%$ of hair transplant surgeries were performed for non-scalp areas, out of which more than $90 \%$ were to the facial area. ${ }^{1}$ This included restoration of eyebrows, eyelashes, beard, and moustache. At our clinic, the trend is similar in that facial hair transplant constitutes about $5 \%$ of our total surgeries. The majority of our facial hair cases are beard and moustache restoration; the remainder are eyebrows (Figure 1).

This article shares our experience on the reconstruction of the beard and moustache.

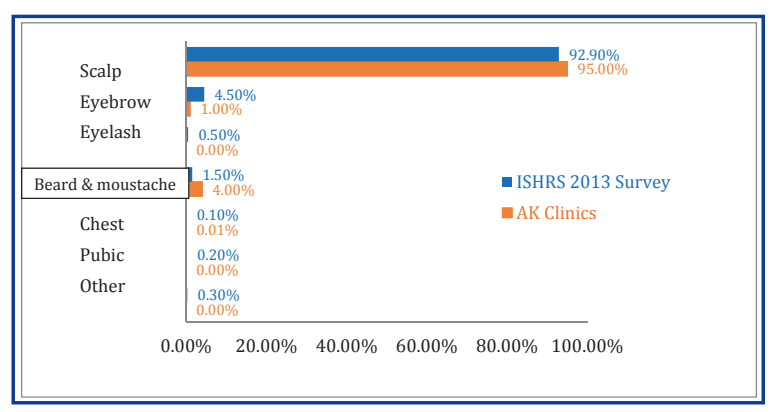

Figure 1. Frequency of hair transplant procedures by body area

Why do patients undergo moustache and beard transplant?

There are a variety of reasons patients choose this type of transplant, and many suffer from the following: 


\section{Facial Hair Transplantation from front page}

- Scars due to trauma, burns, or surgery (Figure 2)

- Traction alopecia (especially in Indian Sikh population) (Figure 3)

- Congenital hypotrichia/atrichia (Figure 4)

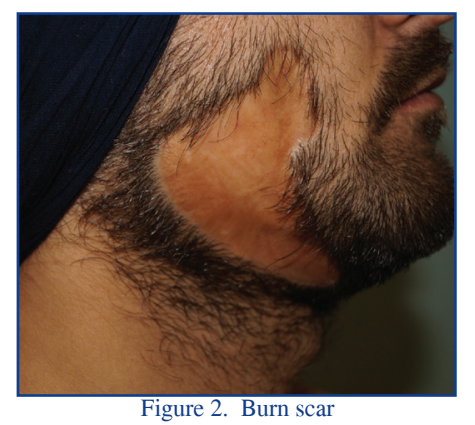

- Post-folliculitis scarring

- Long-standing alopecia areata

In addition, many men simply want to improve the density in certain areas of their beard or moustache depending on certain styles they would like.

\section{Is it any different from the routine scalp hair transplant?}

Yes, it is slightly different from scalp hair transplantation. But before going into the details of the procedure, it is

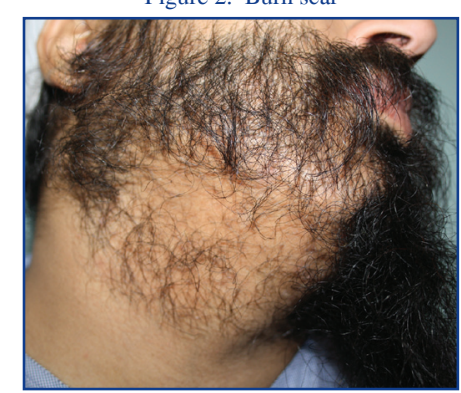

Figure 3. Traction alopecia

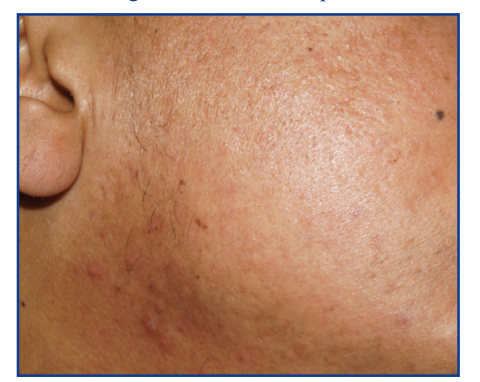

Figure 4. Congenital hypotrichia imperative to review the anatomy of the beard and the difference between the characteristics of the scalp and beard hair.

Beard and moustache hairs consist of mainly single-hair follicular units. The beard growth starts during puberty, under the influence of androgens, and increases in density until the mid30s. This is in contrast to the scalp, where the increased action of androgens causes hair loss. ${ }^{2}$

There are differences among different ethnic groups. Indian and Middle Eastern men have denser beards. ${ }^{3}$ Caucasians and Africans also have good density; they have more hair in the beard compared to Orientals. ${ }^{4}$

For the purpose of facial reconstruction, we divide the face into lateral and frontal aspects (Figure 5). The lateral aspect includes the sideburns, the cheek beard, the jawline beard, and the submandibular beard area. Out of these four areas, the cheek beard

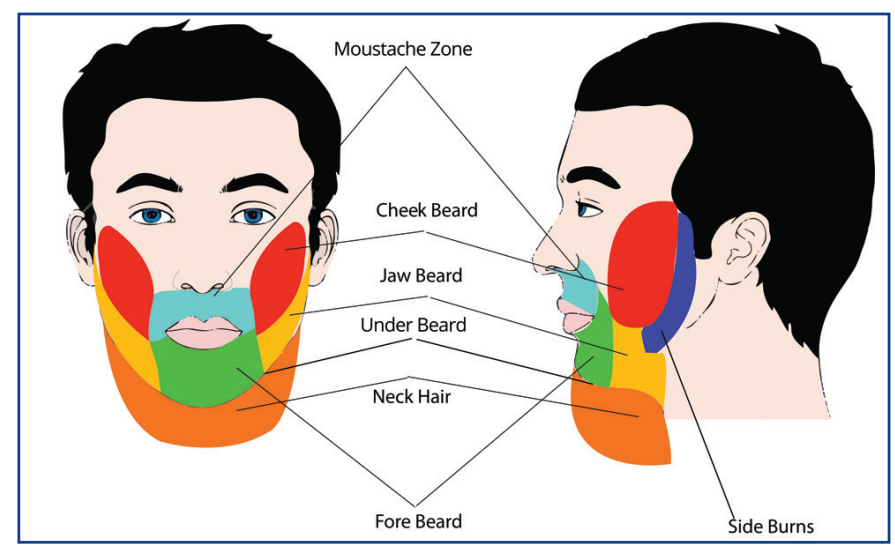

Figure 5. Anatomy of the beard is cosmetically the most important. In the frontal aspect, the fore beard, comprised of the mustache and goatee (chin and sublabial beard), is the prominent feature and higher densities are present in this area. In its pure definition, the goatee does not include the moustache. The hair below the chin and jawline that extends onto the neck is also usually considered to be part of the beard.

The density of the hair is less compared to the scalp. Kulachi reported in a sample of her patients beard density of 25-30 FU/ $\mathrm{cm}^{2}$ and moustache density of $30-45 \mathrm{FU} / \mathrm{cm}^{2} .5$ These figures are probably low for many men. We found that the maximum density was over the chin and mid portion of the moustache. The caliber of the beard hair is more compared to that of the scalp (Figures 6 and 7). Beard hair is also typically more elliptical in shape compared to the circular or oval shape of scalp hair.

\section{Is the planning of a case of facial hair transplant different from that of scalp?}

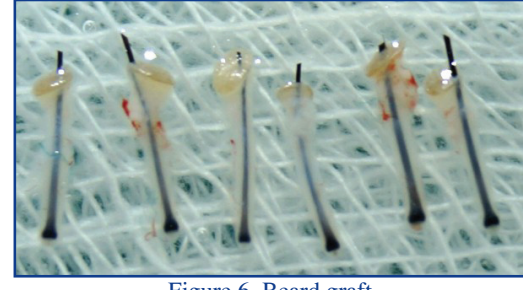

Figure 6. Beard graft

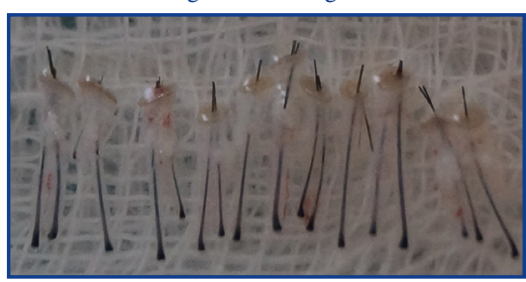

Figure 7. Scalp graft
The basic principles of hair transplantation are the same but need to be planned in a different way. The physician needs to examine the whole face in detail when figuring out how many grafts will be required for every area of the beard and moustache that needs reconstruction. The most common patients that we encounter are the ones with congenital hypotrichia or atrichia. They often need as many as 2,500 grafts to re-create all of the beard and the moustache. Grafts are removed from the donor area in the same way as in a routine FUE. But the main difference is in the distribution of grafts and recipient site creation.

We can harvest with FUT for facial hair reconstruction but for lesser numbers of FUs most of our patients don't want an invasive procedure with sutures and the resulting scar. Beardto-beard is done if small scars are to be reconstructed requiring less than 100-150 grafts or for moustache reconstruction and the patient is willing to take grafts from the area under the chin. For the rest of the cases, scalp-to-beard is preferred.

Out of the seven zones of the beard, the sideburns and the cheek zone are the most important parts in the lateral profile. We prefer coronal slits because they help to ensure alignment of the hair acute to and parallel to the skin. Density is more in the upper part of the sideburn as the hair will grow in a downward direction and will provide better coverage inferiorly due to the overlapping effect of the hair from above. It is the same principle as we use to give a higher density in the part line of the scalp. The total number of grafts usually implanted in this area is around 200 per side.

When we reach the area of the cheek, the slits are directed in a skewed pattern as they turn laterally and downward. But this is quite a big zone and we further divide it into two parts, the border and the body. In the cheek border, we give less density and try to place the single-hair grafts to give it the look of the feathering zone. 


\section{Facial Hair Transplantation from page 139}

The cheek body is where we give a higher density so that the maximum effect of a full beard can be achieved in this area. We usually place 2- and 3-hair grafts of scalp hair in this area. The density is less in the lowermost part of the cheek beard that merges with the jawline beard. There are 500-600 grafts required for the cheek beard on each side.

The jawline beard is again an area where a fullness effect is usually given by the hair layering from above, so a lesser number of grafts is required in that area. We usually do not implant any hair in the under area of the beard in the first sitting, as it is a shadow (or less cosmetically important) area and we want to implant a higher number of grafts in the more visible areas. The only exception is the alopecia caused by traction in the Sikhs, like the one shown in the image above, in which we need to reconstruct the undersurface of the beard (Figure 8).

The frontal aspect is cosmetically more important than the lateral aspect and requires a higher number of grafts compared to the lateral aspects. The total number of grafts for moustache

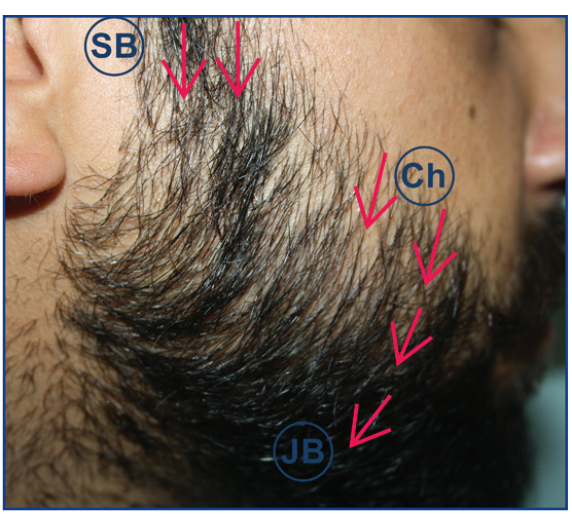

Figure 8. Direction of hair in different beard areas: SB (sideburns)—downward direction; Ch (cheek beard) lateral and downwards; JB (jawline beard)—down and laterally and goatee reconstruction is usually around 1,000-1,100.

The moustache usually needs around 400-500 grafts. The density is higher (around 35-40 FU/ $\mathrm{cm}^{2}$ ) and the hairs are directed downward. We tend to use sagittal slits in this area and make sure that the angle of the slit is as parallel to the skin as possible. We place a slightly higher number of grafts in the upper part as compared to the lower part of the moustache as the layering of the hair compensates for the lesser number of grafts in the bottom part. The single hair grafts are placed in the topmost row to give it a natural look.

The goatee is another area where a higher number of grafts is required (600-700). The main direction of the slits is inferior. In the upper part of the goatee, care must be taken not to apply too much force for making slits, as the skin is thin and the blade could penetrate the oral mucosa.

While making slits, adequate stretching and infiltration of saline is done to make the skin taut, as the facial skin is very loose. Thus, during creation of the recipient slits as well as during implantation, traction by surgeon and counter-traction by the assistant is done to stretch the lax facial tissue. Giving very superficial tumescence also helps to increase the turgidity and thus makes it easier during the procedure. At the time of implantation also, sometimes stretching is required to open the sites (Figure 9).

We usually make pre-made slits, but sometimes, the slits close before graft placement. When this happens, application of counter-traction to stretch the skin will reopen the sites for placement. Sometimes we use the stick-and-place method in which this problem of site closure does not happen.

\section{Donor Area}

We prefer scalp as the donor area for beard, and scalp as well as beard if moustache or small areas of beard are reconstructed. We take out the grafts from the mid-occipital area by FUE and mostly 1 - or 2-hair grafts are extracted (Figures 10 and 11).

\section{Precautions \\ During Implantation}

During implantation, 1-hair grafts are placed over the superior outline similar to scalp hairline, and 1- or 2-hair grafts over the other areas. Two-hair or paired grafts can be used to increase the thickness. Implantation takes a longer time compared to scalp (Figure 12).

\section{What is the technique of giving local anesthesia in the recipient areas?}

Local Anesthesia

Local anesthesia is very painful in the facial area (Figure 13). Therefore, we have started giving nerve

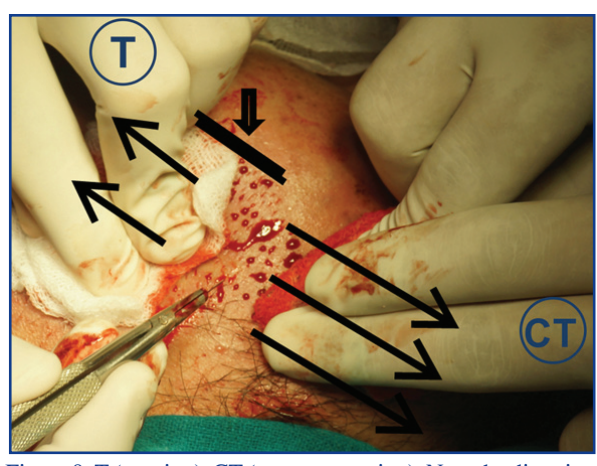
Figure 9. T (traction), CT (counter-traction). Note the direction and acute angle of the blade.

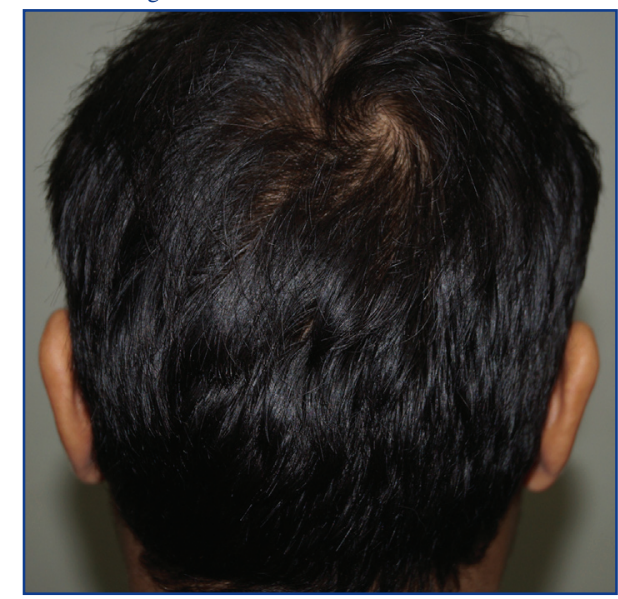

Figure 10. Donor scalp; mid-occipital area is preferred.

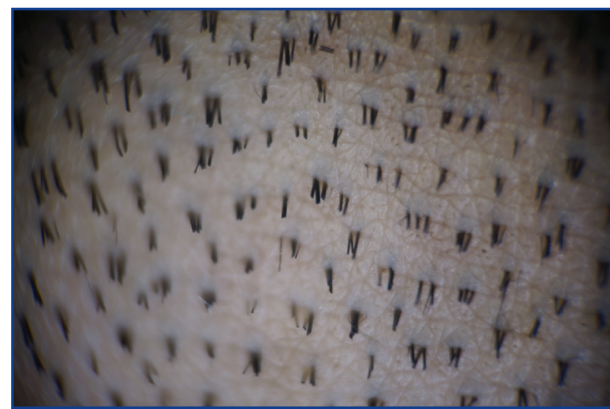

Figure 11. Donor scalp trichogram; 1- and 2-hair grafts preferred

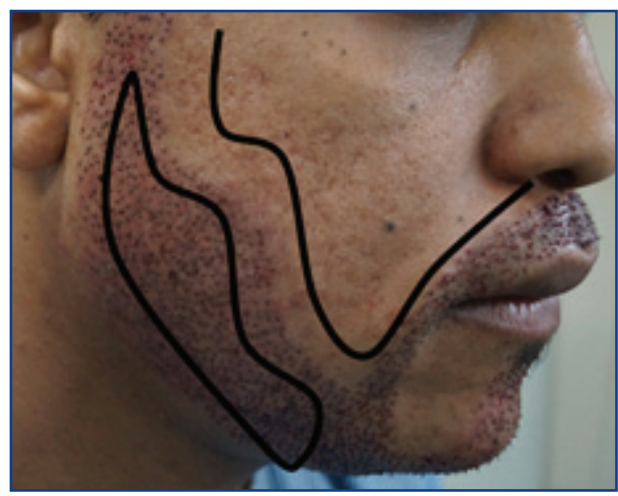

Figure 12. Upper zone for single hair grafts only blocks. The blocks that we give are as follows:

- Auriculotemporal nerve: This is blocked as it ascends in front of the auricle over the posterior root of zygoma, behind the superficial temporal artery. The needle is inserted about $1.5 \mathrm{~cm}$ anterior to the ear, at the level of tragus behind the superficial temporal artery pulsations and around $1 \mathrm{ml}$ of $2 \%$ Lidocaine with 1:200,000 Adrenaline is injected. ${ }^{6}$ This nerve supplies the skin over the parotid gland, the external ear. 


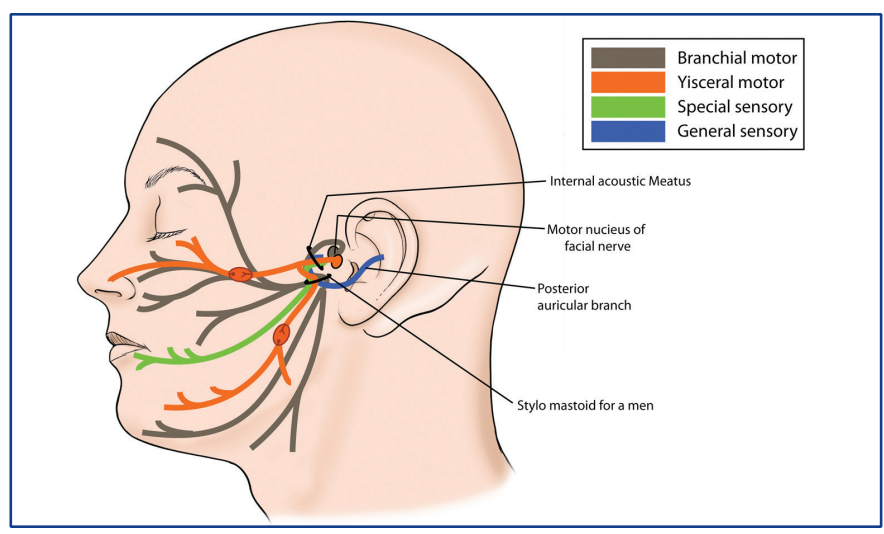

Figure 13. Nerve supply of the face

- Infraorbital nerve: This is blocked by giving $1 \mathrm{ml}$ of the 2\% Lidocaine with 1:200,000 Adrenaline through the intraoral route by inserting the needle vertically upwards with tip pointing towards the foramen in the gingivolabial sulcus between the canine and the first premolar. This anesthetizes the infraorbital area, upper lip, and moustache area.

- Mental nerve: The nerve is blocked as it emerges from the mental foramen, which is located at the gingivolabial sulcus between the two lower premolars $(1 \mathrm{ml}$ of $2 \%$ Lignocaine with 1:200,000 Adrenaline) This helps to numb the lower lip and chin area.

- Long buccal nerve: This is blocked by injecting $2-3 \mathrm{~cm}$ lateral and superior to the angle of the mouth with needle pointing towards mouth and in a fanning manner. This nerve supplies the cheek area.

After the nerve blocks, field anaesthesia is given starting from in front of the ear advancing downward to the lower border of the beard, then across the lower border and then over the upper border (Figure 14).

\section{Post-operative Precautions}

During the post-operative period, some drooling may occur on the first day due to the lo-

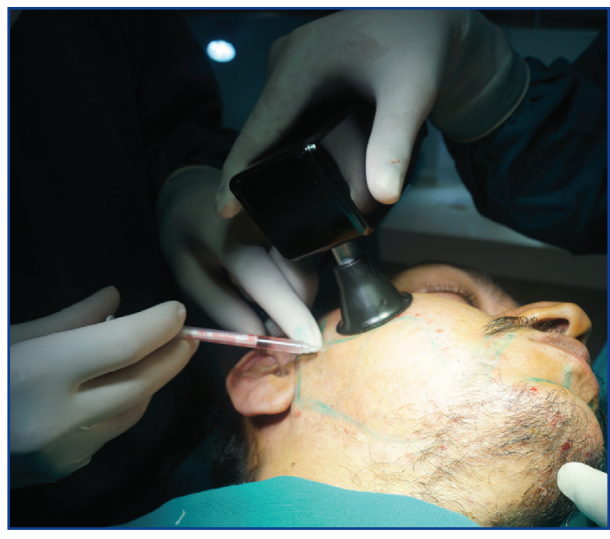

Figure 14. Giving local anesthesia to the beard area cal anesthesia, so we advise semisolids on the day of surgery after discharge. Hair growth begins around 3 months and improves over the next year. Superficial tumescence can also cause post-op ecchymosis, which disappears over a couple of days.

\section{Results after Facial HT} 15-19.

Results from facial transplantation are shown in Figures

\section{References}

1. ISHRS 2013 Practice Census Results.

2. Vogt, A., K.J. McElwee, and U. Blume-Peytavi. Biology of the hair follicle. In: U. Blume-Peytavi, et al., Eds. Hair

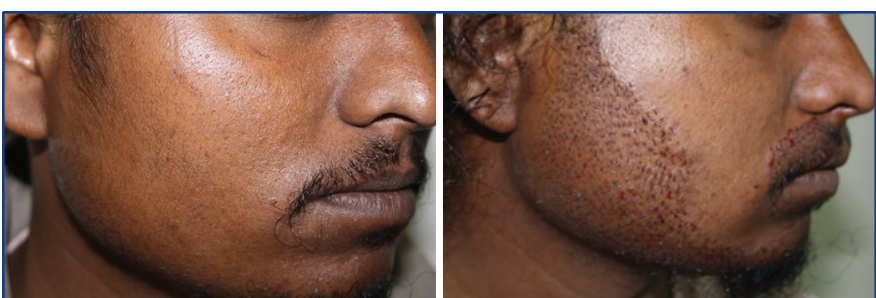

Figure 15. Patient 1, before (left) and immediate post-op (right)

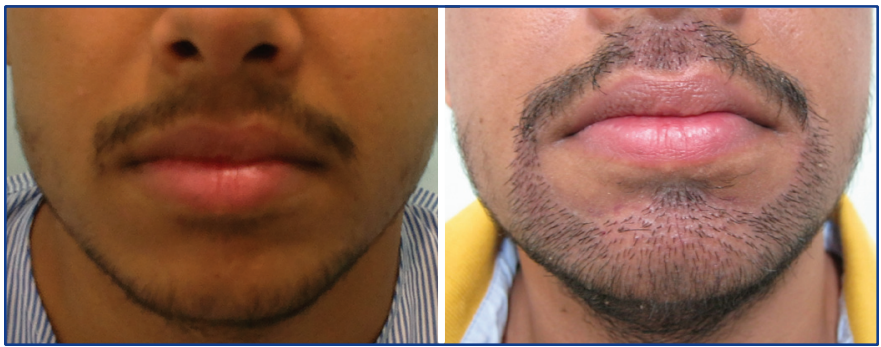

Figure 16. Before (left) and after 1 week (right)

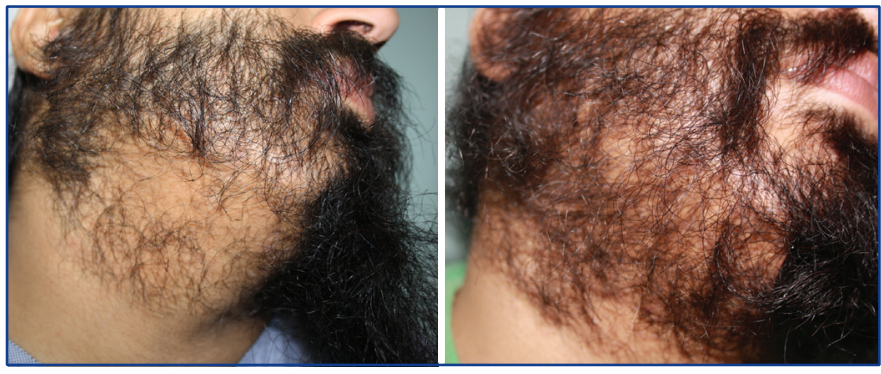

Figure 17. Patient 2, before (left) and after 6 months (right)

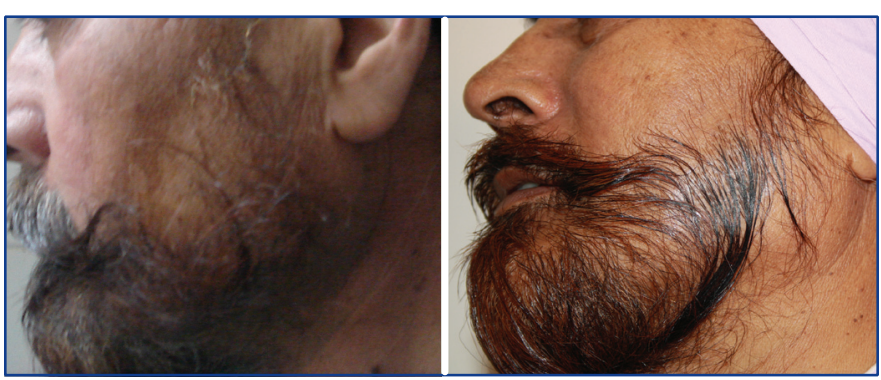

Figure 18. Patient 3, before (left) and (100grafts) after 1 year (right)

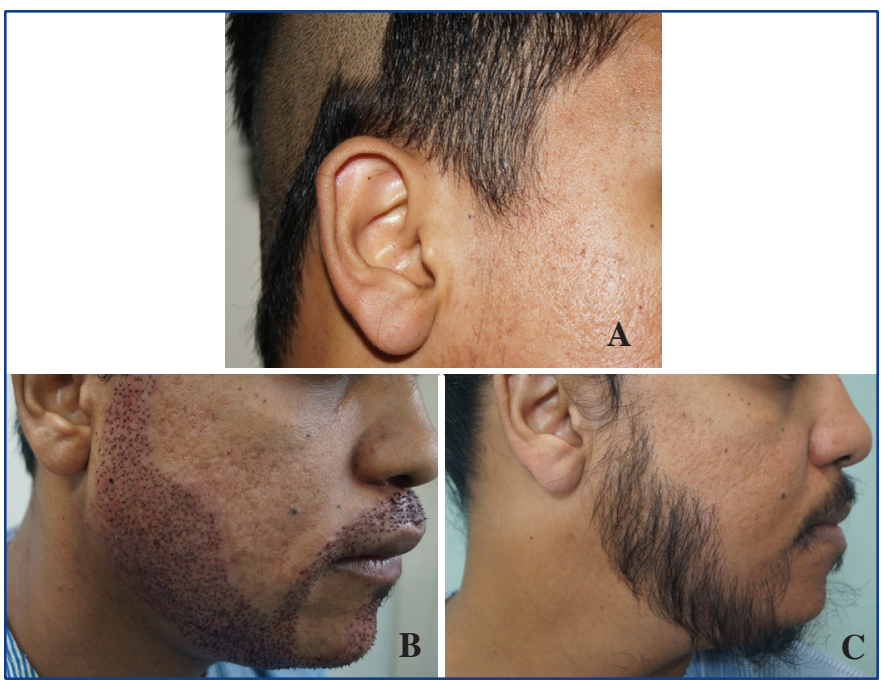

Figure 19. Patient 4 , before surgery $(A)$; immediate post-op $(B)$; and after 2 years $(C)$ 
Facial Hair Transplantation from page 141

Growth and Disorders. 1.8.7 Duration of the Hair Cycle. Table 1.5, page 13 .

3. Gandelman, M., and J.S. Epstein. Reconstruction of the sideburn, moustache, and beard. Facial Plast Surg Clin N Am. 2004; 12:253-261.

4. Pathomvanich, D., and K. Imagawa. Hair restoration surgery in Asians. Part XII. Special procedures in hair restoration surgery: Sideburn transplant and Moustache Transplant.
5. Kulahci, M. Moustache and beard hair transplanting. In: W. Unger and R. Shapiro, eds. Hair Transplantation, 5th Edition. New York: 2011; p. 465.

6. Bebawy, J.F., F. Bilotta, and A. Koht. A modified technique for auriculotemporal nerve blockade when performing selective scalp nerve block for craniotomy. J Neurosurg Anesthesiology. 2014(July); 26(3):271-272.

7. Sanchez, J.P., et al., Eds. Local and regional anaesthetic blocks made simple. Philippines: Nazarene Printers; 2002.

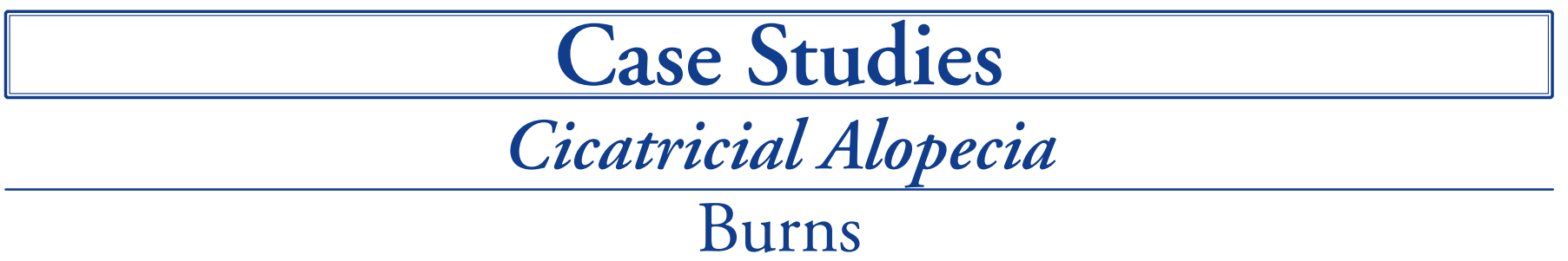

Bessam K. Farjo, MBChB, FISHRS Manchester, England dr.bessam@farjo.com

\section{Diagnosis: Cicatricial Alopecia Secondary to Burns} Method: FUT Strip Scalp to Beard

The 26-year-old patient came to me in 2013. He had burns to his face from scalding at age 5 that resulted in significant scars and the inability to grow a full beard to hide them.

He had no significant family history of hair loss and did not want to shave donor for FUE. We discussed lower yield due to scars. I suggested 1,000 grafts FUT $\times 2$ to achieve density. This was determined based on the size of his recipient area but aiming for a packing rate of 25 per $\mathrm{cm}^{2}$ due to scarring (but also lower requirement for density in the beard).

Surgery was performed in July 2014. There were a total of 1,145 total grafts: $182 \times 1$ 's in $21 \mathrm{G}$ needle incisions placed in the top feathery zone on the cheeks; $674 \times 2$ 's in $19 \mathrm{G}$ needle incisions; and $329 \times 3-4$ 's in $18 \mathrm{G}$ needle incisions in the center of each cheek.

All sites were made perpendicular to hair direction (coronals) to achieve more acute angulation and to avoid graft compression appearance in such a highly visible location.

I have read that it is advised to use 1's and 2's only, however, I think 3's, etc. are ok in this case as you can see in the photos, especially since this patient intends to keep his beard growth to hide the scars.

The patient was given $10 \mathrm{mg}$ diazepam orally pre-op, which the patient responded very well to. If he hadn't, I was prepared to try intravenous diazepam. The face is more sensitive especially in the case of scars.

Otherwise, anesthesia achieved with $1 \%$ lidocaine mixed with 1:200,000 epinephrine in a ring block fashion. The post-op analgesia provided was ibuprofen $600 \mathrm{mg}$ three times a day for 5 days. The patient also was asked to keep his grafts misted with saline every 1.5 hours for 3 days post-op, and then to start gentle dabbing with water before slow washing with hands after day 5 .

Figures 1-3 were taken January 2015 (6 months post-op). The patient is planning to return for another procedure soon.

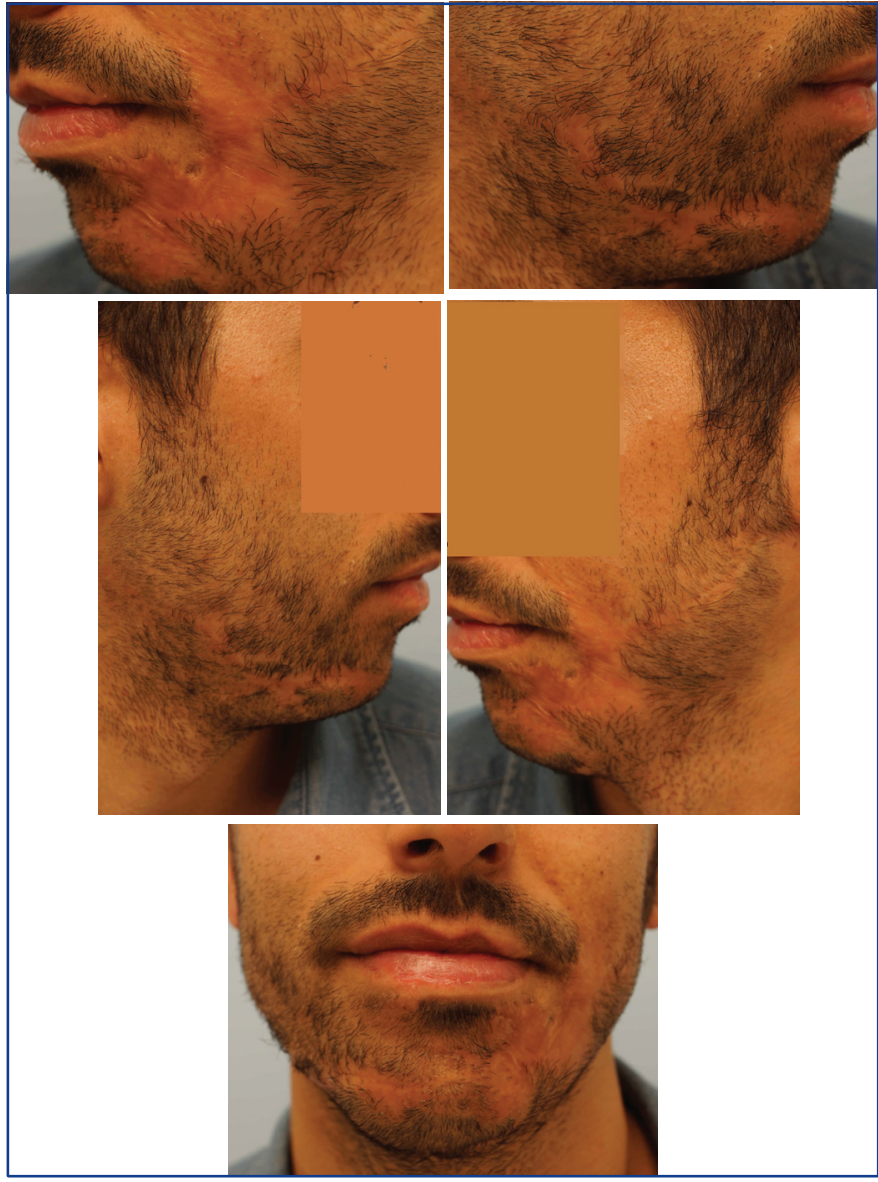

Figure 1. Photos taken before treatment. 